\title{
Kernos
}

Revue internationale et pluridisciplinaire de religion grecque antique

$25 \mid 2012$

Varia

\section{Walter BURKERT, Griechische Religion der archaischen und klassischen Epoche}

\section{Vinciane Pirenne-Delforge}

URL : http://journals.openedition.org/kernos/2042

DOI : $10.4000 /$ kernos.2042

ISSN : 2034-7871

\section{Éditeur}

Centre international d'étude de la religion grecque antique

\section{Édition imprimée}

Date de publication : 26 octobre 2012

Pagination : 329

ISSN : 0776-3824

\section{Référence électronique}

Vinciane Pirenne-Delforge, « Walter BURKERT, Griechische Religion der archaischen und klassischen Epoche », Kernos [En ligne], 25 | 2012, mis en ligne le 01 octobre 2012, consulté le 21 septembre 2020. URL: http://journals.openedition.org/kernos/2042 ; DOI : https://doi.org/10.4000/kernos.2042 


\title{
Walter BURKERT, Griechische Religion der archaischen und klassischen Epoche
}

\author{
Vinciane Pirenne-Delforge
}

\section{RÉFÉRENCE}

Walter BURKERT, Griechische Religion der archaischen und klassischen Epoche, Stuttgart, Kohlhammer, 20112 [1977]. 1 vol. $16 \times 24$ cm, 540 p. (Die Religionen der Menschheit). ISBN : 978-3-17-021312-8.

Walter BURKERT, La religion grecque à l'époque archaïque et classique, traduction et mise à jour bibliographique par Pierre BONNECHERE, Paris, Éditions Picard, 2011. 1 vol. $17 \times 24$ cm, 477 p. (Antiquités/Synthèses). ISBN : 978-2-7084-0906-4.

1 Par un hasard éditorial bienvenu, la 2 édition de l'opus magnum de W. Burkert, revue et corrigée par son auteur, est sortie de presse peu de temps avant la traduction française de l'ouvrage. Soulignons d'emblée que P. Bonnechere (P.B.) a fondé sa traduction sur cette édition revue, mais qu'il a remarquablement contribué à l'inscrire encore davantage dans l'actualité en l'augmentant d'une impressionnante mise à jour bibliographique de plus de 1000 références, réparties tant dans les notes elles-mêmes (un travail titanesque) que dans la bibliographie finale. La traduction française devient dès lors un instrument de travail plus complet encore que la $2^{\mathrm{e}}$ édition allemande.

Il est inutile de s'appesantir sur les mérites d'un ouvrage utilisé depuis 35 ans par ceux qu'intéresse le système religieux des Grecs - la première édition allemande remonte à 1977 - et plus encore depuis que la traduction anglaise a vu le jour en 1985. Il s'agit d'un « classique » auquel la remarquable érudition et la capacité de synthèse de son auteur ont permis de conserver toute sa pertinence. Bien des manuels ont été écrits en trente ans, mais la présente somme n'a pas été dépassée car l'ouvrage peut être mis autant dans les mains de débutants que de chercheurs plus aguerris. Une traduction française en est dès lors tout à fait pertinente, notamment à destination d'étudiants francophones qui risquent de ne pas se pencher spontanément sur un livre écrit dans 
une autre langue que la leur, hélas. Quant aux chercheurs, ils continueront d'y trouver un instrument de travail fourmillant de notations intéressantes (un nouveau paragraphe sur la magie referme la section "Rituel et sanctuaire») et de problématiques que la mise à jour bibliographique permet de nourrir des débats les plus récents. Il faut simplement ajouter désormais à cette bibliographie le dernier livre de Robert Parker, On Greek Religion, et celui de Henk S. Versnel, Coping with the Gods ${ }^{1}$. Pour saisir toutes les implications de ces deux derniers ouvrages, notamment sur des questions de méthode, un passage préalable par le manuel de Burkert peut être vivement conseillé !

Walter Burkert est un très grand savant, d'un format qui tend à disparaître, si j'ose ainsi m'exprimer. Durant toute sa carrière, il a évité le piège de l'hyperspécialisation qui nous guette tous, en s'ouvrant à d'autres disciplines, en élargissant le spectre chronologique et géographique de ses recherches d'une manière remarquable, quelles que soient les divergences de vue qui peuvent surgir de la méthode d'approche ainsi mise en œuvre. Pour saisir une telle richesse, outre des monographies comme Homo Necans, Structure and History, ou Creation of the Sacred (parmi bien d'autres), la lecture des huit volumes de ses Kleine Schriften est saisissante. C'est une œuvre de grande envergure à laquelle on a affaire et, de ce puissant édifice, le présent ouvrage est incontestablement un des piliers parmi les plus solides et les plus durables.

\section{NOTES}

1. Voir ici-même la recension conjointe de ces deux livres par Pierre Bonnechere.

\section{AUTEURS}

\section{VINCIANE PIRENNE-DELFORGE}

F.R.S.-FNRS - Université de Liège 